IN THE NAME OF WOMEN'S RIGHTS 
This page intentionally left blank 


\title{
IN THE NAME OF WOMEN'S RIGHTS
}

\author{
The Rise of Femonationalism
}

SARA R. FARRIS

DUKE UNIVERSITY PRESS

Durham and London 2017 
(C) 2017 Duke University Press

All rights reserved

Printed in the United States

of America on acid-free paper $\infty$

Typeset in Minion Pro by Westchester Publishing Service

Library of Congress Cataloging-in-Publication Data

Names: Farris, Sara R., author.

Title: In the name of women's rights : the rise of

femonationalism / Sara R. Farris.

Description: Durham : Duke University Press, 2017. |

Includes bibliographical references and index.

Identifiers: LCCN 2016047057 (print)

LCCN 2016049128 (ebook)

ISBN 9780822369608 (hardcover : alk. paper)

ISBN 9780822369745 (pbk. : alk. paper)

ISBN 9780822372929 (ebook)

Subjects: LCSH: Europe-Emigration and immigration. |

Women's rights-Religious aspects. | Islamophobia-

Political aspects-Europe. | Immigrants-Europe-Public

opinion. | Women immigrants-Employment-Europe. |

Feminism. | Nationalism.

Classification: LCC JV7590.F368 2017 (print)|

LCC JV7590 (ebook) | DDC 323.3/4094-dc23

LC record available at https://lccn.loc.gov/2016047057

Cover art: Adji Baifall Minaret, 2004. (C) Maïmouna

Guerresi. 
FOR MARIA AND ANTONIO,

MY PARENTS 
This page intentionally left blank 